\title{
The Toll-Like Receptor 4 D299G and T399I Polymorphisms Are Associated with Crohn's Disease and Ulcerative Colitis: A Meta-Analysis
}

\author{
Xiuyun Shen ${ }^{\mathrm{a}}$ Ruihua Shi ${ }^{\mathrm{a}}$ Hongjie Zhang ${ }^{\mathrm{a}}$ Kebei Li ${ }^{\mathrm{a}}$ Yang Zhao $^{\mathrm{b}}$ \\ Ruyang Zhang ${ }^{\text {b }}$ \\ a Department of Gastroenterology, First Affiliated Hospital of Nanjing Medical University, and \\ ${ }^{b}$ Department of Epidemiology and Biostatistics, School of Public Health, Nanjing Medical University, Nanjing, China
}

\section{Key Words}

Toll-like receptor $4 \cdot$ Polymorphism $\cdot$ Crohn's disease, susceptibility · Ulcerative colitis, susceptibility .

Meta-analysis

\begin{abstract}
Background: Some studies have reported that Toll-like receptor 4 (TLR4) D299G and T399l polymorphisms are associated with increased Crohn's disease (CD) and ulcerative colitis (UC) risk in the Caucasian population. However, the results have been inconsistent. Methods: A systemic review of the published data (16 studies with 8,387 cases and 7,013 controls for D299G; 8 studies with 3,881 cases and 1,861 controls for T399l) was undertaken and a meta-analysis was performed to test whether TLR4 D299G and T399l polymorphisms were associated with CD or UC susceptibility and whether 299Gly carriage was associated with phenotypes of CD patients. Results: The TLR4 299Gly allele showed a significant association with $C D$ and $U C$ in the Caucasian population (OR 1.29, 95\% Cl 1.08-1.54, and OR 1.28, 95\% Cl 1.08-1.51, respectively). Similar association was detected between the T399I polymorphism and susceptibility to CD and UC (OR $1.37,95 \% \mathrm{Cl} 1.12-1.68$, and OR $1.46,95 \% \mathrm{Cl} 1.13-1.88$, respec-
\end{abstract}

tively). However, no significant association was identified between CD phenotypes and 299Gly carriage. Conclusion: The meta-analysis showed that TLR4 D299G and T399I confer a significant risk for developing CD and UC in Caucasians. Additional well-powered studies of the association between TLR4 variants and UC are needed.

Copyright $\odot 2010$ S. Karger AG, Basel

\section{Introduction}

Inflammatory bowel disease (IBD), comprising Crohn's disease (CD) and ulcerative colitis (UC), is a complex disorder characterized by chronic inflammation of the gastrointestinal tract. The etiology of IBD is still unclear, its pathogenesis seems to be multifactorial, and both genetic and environmental factors play important roles. A genetic predisposition, through the inheritance of a number of contributory genetic polymorphisms, contributes to the pathogenesis of IBD.

The identification of the first major susceptibility gene for CD encoding NOD2/CARD15 confirmed the critical role of enteric bacteria and their interaction with the intestinal innate mucosal immune system in the pathogen-

\section{KARGER}

Fax +4161306 1234 E-Mail karger@karger.ch www.karger.com
(C) 2010 S. Karger AG, Basel 0012-2823/10/0812-0069 $\$ 26.00 / 0$

Accessible online at: www.karger.com/dig
Prof. Ruihua Shi

Department of Gastroenterology

First Affiliated Hospital of Nanjing Medical University

300 Guangzhou Road, Nanjing 210029 (China)

Tel. +86 258371 8836, ext. 6032, Fax +86 258367 4636, E-Mail ruihuashi@ 126.com 
esis of this disorder. Recognition of the key role of innate mucosal immunity in CD implicates a potential role for other germ-line encoded pattern recognition receptors, like the various cell surface Toll-like receptors (TLRs) which recognize different pathogen-associated molecular patterns shared by many pathogens but not expressed by the host.

TLR4 is a member of the interleukin-1 receptor (IL$1 \mathrm{R}) /$ TLR superfamily $[1,2]$. As the major transducer of lipopolysaccharide (LPS) which is the generally accepted inducer of the inflammatory response to Gram-negative bacteria, TLR 4 has attracted great attention. Recent studies have described low TLR4 expression in healthy human intestinal biopsies and significantly increased expression of TLR4 in intestinal epithelial cells, resident macrophages, and dendritic cells (DCs) in the inflamed mucosa of IBD patients [3-6]. The signal transduction pathway of TLR4 is partially known: LPS is opsonized by LPS-binding protein (LBP) and subsequently recognized by CD14. A LPS-LBP-CD14 complex then activates TLR4, which signals through adaptor protein MyD88 and serine kinase IL-1R-associated kinase 4 and another adaptor protein TNF receptor-associated factor 6 . This finally results in activation of NF- $\kappa$ B and mitogen-activated protein kinases and triggers cytokine production $[7,8]$.

The TLR4 variants Asp299Gly (299 A>G, D299G, rs4986790) and Thr399Ile (399 C>T, T399I, rs4986791) have been described to affect the response of this receptor to LPS. In addition to several in vitro transfection experiments indicating the relation of Asp299Gly with decreased response to LPS, a recent study concerning the two non-synonymous, co-segregating single nucleotide polymorphisms (SNPs) of the TLR4 gene by Arbour et al. [9] reported that the airway responsiveness to inhaled LPS was significantly lower in subjects heterozygous or homozygous for the Asp299Gly and Thr399Ile alleles than in those with the wild-type genotype. In accordance with these observations, protective effects of the two SNPs to IBD would be expected.

A number of studies have assessed the association between the TLR4 polymorphisms and IBD in different populations, however, the results are inconsistent and inconclusive [10-31]. Due to the different methodologies and the small sample sizes used in most studies, there has been a lack of replication in the various studies. By using all the available published data to increase statistical power, it was hypothesized that a meta-analysis might allow plausible candidate genes to be excluded and causative genes to be identified with reliability.
Therefore, a meta-analysis was performed in which all published case-control studies in the Caucasian population were processed to confirm whether the D299G and T399I polymorphisms of TLR4 increase the risk of IBD in Caucasians, and furthermore to identify the correlation between 299 Gly carriage and CD phenotypes.

\section{Methods}

Inclusion Criteria

Identification of the studies was carried out through a search of Medline and Embase for relative articles published up to March 31, 2009, using the following terms: (1) Toll-like receptor (TLR); (2) Crohn's disease and ulcerative colitis, and (3) polymorphism or variant or genotype. A cited reference search of the retrieved articles was carried out, and publications were also identified by reviewing the bibliographies of the retrieved articles. Studies included were limited to the Caucasian population. Eligible studies reported sufficient data to calculate the number of each allele identified or odds ratios (ORs) and confident intervals (CIs) for carriage of the mutant allele. Studies whose allele frequency in the control population deviated from the Hardy-Weinberg equilibrium at a $\mathrm{p}$ value of $\leq 0.05$ were excluded from the meta-analysis. If more than one article was published by the same author using the same case series, we selected the study in which the most individuals were included.

\section{Data Extraction}

A standard reporting form was used to abstract the data from each publication, which includes: first author's name; year of publication; country in which the study was carried out; ethnicity; age range of study subjects; allele frequencies; ORs; confident intervals; sample sizes, and clinical characteristics. Data were extracted independently and in duplicate by 2 investigators. The results were compared and disagreements were resolved by consensus.

\section{Statistical Analysis}

The meta-ORs were estimated using a fixed-effects model with the wild-type allele as reference group. For each outcome, the between-study heterogeneity was tested by $\mathrm{Q}$ and $\mathrm{I}^{2}$ statistics. A $p$ value of $<0.05$ was considered significant for the $\chi^{2}$-based $Q$ testing and $\mathrm{I}^{2}$ was interpreted as the proportion of total variation contributed by the between-study variation. Data were recombined by using a random-effects model when heterogeneity existed. To determine deviation from Hardy-Weinberg equilibrium we used a publicly available program (http://ihg.gsf.de/cgi-bin/ hw/hwal.pl). A visual inspection of the funnel plot was used to investigate for publication bias. All the meta-analyses were conducted by Review Manager 4.2 software (http://www.cochrane. org/cochrane/hbook.htm) on a personal computer.

\section{Genotype-Phenotype Meta-Analysis}

In addition to a case-control meta-analysis, we also performed a genotype-phenotype meta-analysis for CD patients. The metaanalysis used the Vienna classification because previous studies that have reported genotype-phenotype data stratified by Asp299Gly status have used the Vienna classification. Among CD 
Table 1. Pooled analysis of studies exploring the role of TLR4 299Gly in IBD

\begin{tabular}{|c|c|c|c|c|c|}
\hline \multirow[t]{2}{*}{ Population } & \multirow{2}{*}{$\begin{array}{l}\text { Number } \\
\text { of cases }\end{array}$} & \multicolumn{3}{|c|}{ Odds ratio $(95 \% \mathrm{CI})$} & \multirow[t]{2}{*}{ Reference } \\
\hline & & $\mathrm{CD}$ & $\mathrm{UC}$ & IBD & \\
\hline Scotland & 480 & $1.28(0.81-2.04)$ & $0.81(0.49-1.33)$ & $1.03(0.68-1.57)$ & Arnott et al. [22], 2004 \\
\hline Belgium & 610 & $2.34(1.32-4.18)$ & $2.05(1.07-3.93)$ & $2.27(1.29-4.00)$ & Franchimont et al. [23], 2004 a \\
\hline Belgium & 318 & $1.79(1.14-2.82)$ & ND & $1.68(1.13-2.52)$ & Franchimont et al. [23], 2004 \\
\hline Germany & 200 & $1.75(0.81-3.77)$ & $2.28(1.09-4.79)$ & $2.01(1.04-3.89)$ & Torok et al. [14], 2004 \\
\hline Germany & 204 & $2.03(1.07-3.86)$ & ND & $2.03(1.07-3.86)$ & Brand et al. [13], 2005 \\
\hline The Netherlands & 637 & $1.89(1.03-3.48)$ & $1.24(0.63-2.46)$ & $1.65(0.91-3.00)$ & Braat et al. [20], 2005 \\
\hline Italy & 23 & $2.71(0.37-19.89)$ & ND & $2.71(0.37-19.89)$ & Fries et al. [26], 2005 \\
\hline Hungary & 527 & $0.8(0.49-1.30)$ & ND & $0.8(0.49-1.30)$ & Lakatos et al. [25], 2005 \\
\hline The Netherlands & 591 & $1.55(0.96-2.50)$ & $1.32(0.74-2.38)$ & $1.47(0.94-2.31)$ & Oostenbrug et al. [11], 2005 \\
\hline The Netherlands & 112 & $2.18(1.15-4.15)$ & ND & $2.18(1.15-4.15)$ & Ouburg et al. [21], 2005 \\
\hline New Zealand & 182 & $0.81(0.47-1.40)$ & ND & $0.81(0.47-1.40)$ & Hong et al. [18], 2006 \\
\hline Hungary & 386 & $0.95(0.59-1.53)$ & $1.43(0.86-2.39)$ & $1.12(0.75-1.69)$ & Baumgart et al. [24], 2007 \\
\hline Germany & 262 & $1.84(0.78-4.35)$ & $1.65(0.57-4.80)$ & $0.69(0.53-0.89)$ & Baumgart et al. [24], 2007 \\
\hline New Zealand & 791 & $1.24(0.82-1.89)$ & $1.20(0.79-1.83)$ & $1.22(0.85-1.77)$ & Browning et al. [17], 2007 \\
\hline The Netherlands & 707 & $2.20(1.33-3.66)$ & $1.88(1.08-3.30)$ & $2.09(1.28-3.40)$ & De Ridder et al. [12], 2007 \\
\hline Australia & 619 & $1.47(0.99-2.20)$ & $\mathrm{ND}$ & $1.47(0.99-2.20)$ & Hume et al. [27], 2008 \\
\hline Italy & 178 & $0.97(0.37-2.49)$ & $0.85(0.22-3.28)$ & $0.94(0.38-2.30)$ & Rigoli et al. [16], 2008 \\
\hline Canada & 160 & $1.00(0.56-1.78)$ & ND & $1.00(0.57-1.74)$ & De Jager et al. [31], 2007a \\
\hline Canada & 114 & $0.86(0.32-2.27)$ & ND & $0.86(0.32-2.27)$ & De Jager et al. [31], 2007 \\
\hline Belgium & 249 & $1.39(0.99-1.95)$ & $1.09(0.66-1.80)$ & $1.11(0.65-2.07)$ & De Jager et al. [31], 2007 \\
\hline Belgium & 104 & $0.89(0.34-2.30)$ & ND & $1.00(0.57-1.74)$ & De Jager et al. [31], 2007 \\
\hline NIDDK & 933 & $1.00(0.71-1.41)$ & $1.03(0.64-1.66)$ & $1.02(0.77-1.35)$ & De Jager et al. [31], 2007 \\
\hline All studies & 8,387 & $1.29(1.08-1.54)$ & $1.28(1.08-1.51)$ & $1.25(1.06-1.48)$ & \\
\hline $\mathrm{p}$ value & & 0.004 & 0.004 & 0.007 & \\
\hline
\end{tabular}

$\mathrm{CD}=$ Crohn's disease; UC = ulcerative colitis; IBD = inflammatory bowel disease; $\mathrm{CI}=$ confidence interval; NIDDK = National Institute of Diabetes and Digestive and Kidney Diseases; ND = no data, data not available from the published paper.

a These studies included more than one cohort which are numbered in the listed sequence and presented in figures 1-3.

patients, we compared the odds of having a 299Gly variant for age $<40$ years (A1) versus age $\geq 40$ years (A2); male versus female; stricturing (B2) and penetrating (B3) versus non-stricturing, non-penetrating (B1) patients; ileal (L1) and ileocolonic (L3) versus colonic (L2) patients, and patients who experienced surgical intervention versus those who did not.

\section{Results}

\section{Studies on TLR4 D299G}

Twenty-two case-control studies were identified for IBD [10-31], 17 of which concerned both UC and CD while the other 5 articles just focused on CD. Of the 22 studies, 5 were excluded because the study population was non-Caucasian $[10,19,28,29]$ or the ethnic background was not clear [30], and study was excluded due to failure of Hardy-Weinberg equilibrium [15]. So the exact number of studies included in our analyses was 16 (3 of them contained more than one cohort [23, 24, 31]), including 8,387 cases of IBD and 7,013 controls (table 1).

\section{Studies on TLR4 T399I}

Ten studies were identified for IBD [10-19]. Of these, 2 were excluded because the study population was non-Caucasian $[10,19]$. So the final number of studies included in the analyses was 8, with 3,881 IBDs and 1,861 controls (online supplementary table 1, www. karger.com/doi/10.1159/000260417).

\section{Studies on TLR4 D299G Genotype-CD Phenotypes Correlations}

Most of the studies which assessed the contribution of TLR4 variants to IBD susceptibility have tried to identify 


\begin{tabular}{|c|c|c|c|c|c|c|c|}
\hline \multirow{2}{*}{$\begin{array}{l}\begin{array}{l}\text { Study } \\
\text { or subcategory }\end{array} \\
\text { Arnott et al. [22] }\end{array}$} & \multirow{2}{*}{$\begin{array}{l}\mathrm{CD} \\
\mathrm{n} \\
234\end{array}$} & \multirow{2}{*}{$\begin{array}{l}\mathrm{HC} \\
\mathrm{n} \\
189\end{array}$} & \multirow{2}{*}{$\begin{array}{l}\text { log [odds ratio] } \\
\text { (SE) } \\
0.2468(0.2356)\end{array}$} & \multicolumn{2}{|c|}{$\begin{array}{l}\text { Odds ratio (random) } \\
95 \% \mathrm{Cl}\end{array}$} & \multirow{2}{*}{$\begin{array}{l}\text { Weight } \\
\%\end{array}$} & \multirow{2}{*}{$\begin{array}{l}\text { Odds ratio (random) } \\
95 \% \mathrm{Cl} \\
1.28(0.81,2.03)\end{array}$} \\
\hline & & & & & & & \\
\hline Baumgart et al. [24], 1 & 241 & 403 & $-0.0512(0.2430)$ & & & 5.24 & $0.95(0.59,1.53)$ \\
\hline Baumgart et al. [24], 2 & 144 & 202 & $-0.3778(0.1330)$ & $\longrightarrow-$ & & 7.18 & $0.69(0.53,0.89)$ \\
\hline Braat et al. [20] & 411 & 137 & $0.6365(0.3105)$ & & & 4.21 & $1.89(1.03,3.47)$ \\
\hline Brand et al. [13] & 204 & 199 & $0.7080(0.3272)$ & & & 3.99 & $2.03(1.07,3.85)$ \\
\hline Browning et al. [17] & 386 & 402 & $0.2151(0.2130)$ & & $=$ & 5.75 & $1.24(0.82,1.88)$ \\
\hline De Jager et al. [31], 1 & 135 & 320 & $0.0000(0.2950)$ & & & 4.43 & $1.00(0.56,1.78)$ \\
\hline De Jager et al. [31], 2 & 114 & 68 & $-0.1508(0.4997)$ & & & 2.33 & $0.86(0.32,2.29)$ \\
\hline De Jager et al. [31], 3 & 449 & 479 & $0.3293(0.1729)$ & & & 6.47 & $1.39(0.99,1.95)$ \\
\hline De Jager et al. [31], 4 & 83 & 208 & $-0.1165(0.4876)$ & & & 2.42 & $0.89(0.34,2.31)$ \\
\hline De Jager et al. [31], 5 & 593 & 1,866 & $0.0000(0.1750)$ & & & 6.43 & $1.00(0.71,1.41)$ \\
\hline De Ridder et al. [12] & 450 & 244 & $0.7884(0.2582)$ & & & 4.99 & $2.20(1.33,3.65)$ \\
\hline Franchimont et al. [23], 1 & 447 & 139 & $0.8501(0.2940)$ & & & 4.44 & $2.34(1.32,4.16)$ \\
\hline Franchimont et al. [23], 2 & 252 & 636 & $0.5822(0.2310)$ & & & 5.44 & $1.79(1.14,2.81)$ \\
\hline Fries et al. [26] & 23 & 59 & $0.9969(1.0164)$ & & & 0.71 & $2.71(0.37,19.87)$ \\
\hline Hong et al. [18] & 182 & 188 & $-0.2107(0.2784)$ & & & 4.67 & $0.81(0.47,1.40)$ \\
\hline Hume et al. [27] & 619 & 360 & $0.3852(0.2037)$ & & & 5.92 & $1.47(0.99,2.19)$ \\
\hline Lakatos et al. [25] & 527 & 200 & $-0.2231(0.2489)$ & & - & 5.14 & $0.80(0.49,1.30)$ \\
\hline Oostenbrug et al. [11] & 393 & 296 & $0.4382(0.2441)$ & & & 5.22 & $1.55(0.96,2.50)$ \\
\hline Ouburg et al. [21] & 112 & 170 & $0.7793(0.3273)$ & & & 3.99 & $2.18(1.15,4.14)$ \\
\hline Rigoli et al. [16] & 133 & 103 & $-0.0304(0.4863)$ & & & 2.42 & $0.97(0.37,2.52)$ \\
\hline Torok et al. [14] & 102 & 145 & $0.5596(0.3920)$ & & & 3.24 & $1.75(0.81,3.77)$ \\
\hline \multirow{4}{*}{$\begin{array}{l}\text { Total }(95 \% \mathrm{Cl}) \\
\text { Test for heterogeneity: } \chi^{2} \\
\text { Test for overall effect: } Z=\end{array}$} & & & & & & 100.00 & $1.29(1.08,1.54)$ \\
\hline & 51.98 & $f_{.}=21$ & $0.0002), I^{2}=59.6 \%$ & & & & \\
\hline & & & 0.2 & 0.5 & 2 & 5 & \\
\hline & & & & Favors HC & Favor & & \\
\hline
\end{tabular}

Fig. 1. Significant association between TLR4 299G allele and CD risk (OR 1.29, 95\% CI 1.08-1.54, p = 0.004). Significant heterogeneity was shown among studies. $n=$ Number of CD patients or healthy controls (HC). The numbers after some of the study references are the cohort numbers.

the correlation between the D299G variant and clinical characteristics in CD patients. However, most of the raw data were not available, even after contacting the authors. Finally, we extracted D299G data stratified by age at CD onset from 4 previous studies [11, 13, 18, 21], D299G data stratified by gender from 2 previous studies [11, 13], D299G data stratified by disease location from 5 previous studies [11, 13, 18, 20, 21], D299G data stratified by disease behavior from 4 previous studies $[11,13,18,21]$, and D299G data stratified by need of surgical intervention from 3 previous studies [13, 18, 21].

\section{Association of TLR4 D299G Polymorphism with IBD}

Susceptibility

We observed a significant association between the G allele and both CD and UC risk based on the 16 studies published so far. The ORs for the G allele were 1.29 (95\% CI
$1.08-1.54, \mathrm{p}=0.004$; fig. 1$)$ and 1.28 (95\% CI 1.08-1.51, $\mathrm{p}=$ 0.004; fig. 2) for CD and UC, respectively, and 1.25 (95\% CI 1.06-1.48, $\mathrm{p}=0.007$; fig. 3 ) for IBD patients as whole.

\section{Association of TLR4 T399I Polymorphism with IBD Susceptibility}

Similar to the D299G polymorphism, an association was also observed between the T allele and CD and UC in the Caucasian population. The ORs for the $\mathrm{T}$ allele were 1.37 (95\% CI 1.12-1.68, $\mathrm{p}=0.002)$ and $1.46(95 \% \mathrm{CI}$ $1.13-1.88, \mathrm{p}=0.003$ ) for $\mathrm{CD}$ and $\mathrm{UC}$, respectively (online suppl. table 1).

\section{TLR4 D299G Genotype-CD Phenotypes Correlations}

The genotype-phenotype meta-analysis did not identify any significant associations between 299Gly carriage and CD phenotypes, including age at onset (OR 0.64, 95\% 


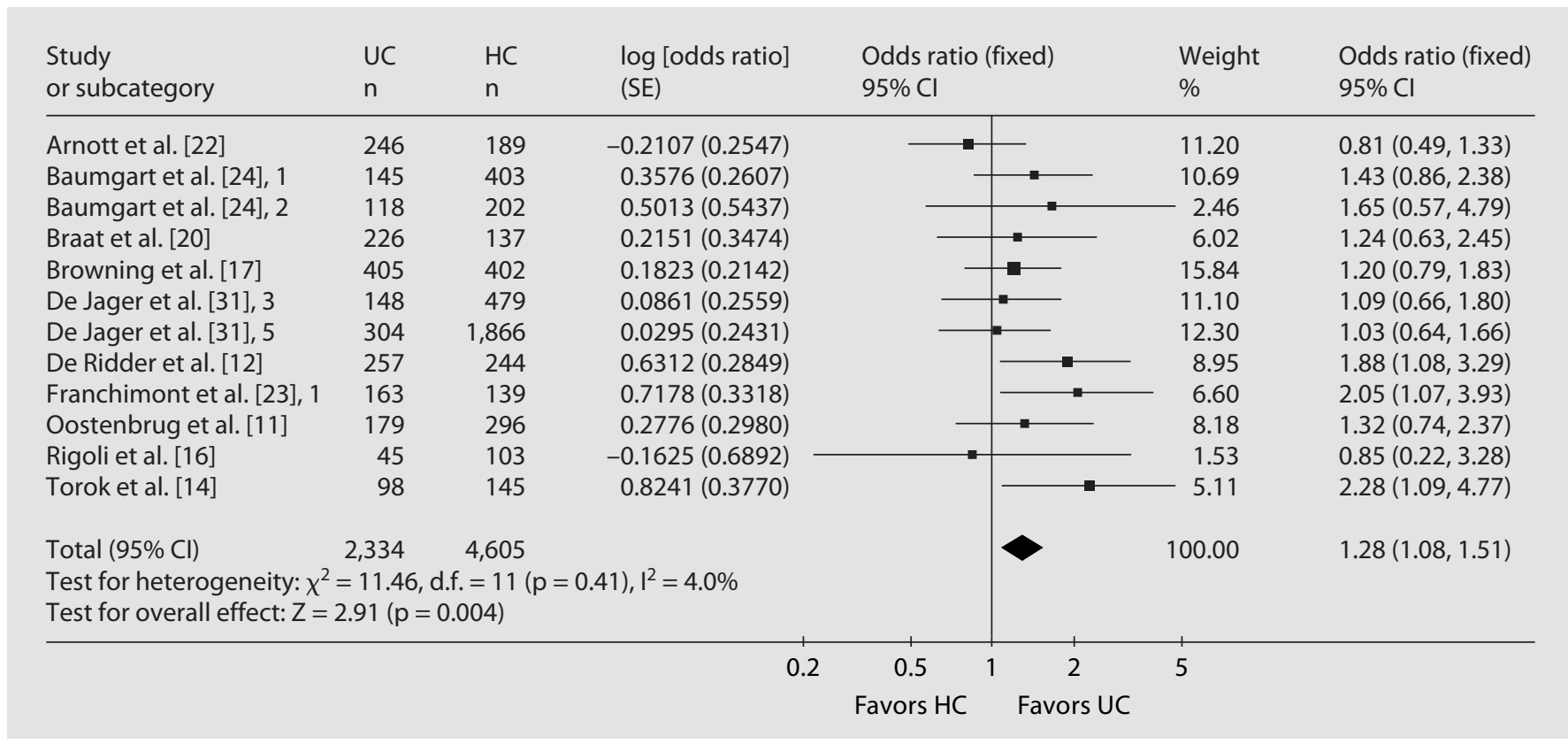

Fig. 2. Significant association between TLR4 299G allele and UC risk (OR 1.28, 95\% CI 1.08-1.51, p = 0.004). There was no significant heterogeneity among studies. $n=$ Number of UC patients or healthy controls (HC). The numbers after some of the study references are the cohort numbers.

CI $0.39-1.05, \mathrm{p}=0.08)$, gender (OR 1.17, 95\% CI 0.72-1.90, $\mathrm{p}=0.54)$, small bowel involvement (OR $0.68,95 \% \mathrm{CI}$ $0.19-2.40, \mathrm{p}=0.55$ for ileal versus colonic, and OR 0.70 , $95 \%$ CI $0.23-2.13, \mathrm{p}=0.53$ for ileocolonic versus colonic), disease behavior (OR 1.08, 95\% CI 0.63-1.86, $\mathrm{p}=0.78$ for stricturing versus non-stricturing, non-penetrating, and OR $0.87,95 \%$ CI $0.45-1.67, \mathrm{p}=0.67$ for penetrating versus non-stricturing, non-penetrating) and need of surgery (OR 0.82, 95\% CI 0.53-1.26, $\mathrm{p}=0.36$ ).

\section{Discussion}

The TLR4 gene is located on chromosomal region 9q. Unlike most recently discovered candidate genes such as IL-23R and ATG16L1, the region under the TLR4 gene was not implicated in previous genome scans [32-34]. In 2004, Franchimont et al. [23] reported a significant association between the Asp299Gly polymorphism and both $\mathrm{CD}$ and UC in a population most of which were Caucasians. A number of studies on the association of TLR4 Asp299Gly polymorphism with IBD have been carried out since then and have reported conflicting results. However, most of them have shown an increased frequency of the 299 Gly allele in CD and UC patients com- pared to controls [11, 13, 14, 20, 22, 23, 25]. Our metaanalyses showed a significant association between the TLR4 D299G polymorphism and CD and UC risk in the Caucasian population samples. The results support that TLR4 299G may be a risk factor for CD, which is in line with several previous published meta-analyses $[17,18,27$, 31]. A correlation between the D299G polymorphism and UC has been rarely discussed, and research by De Jager et al. [31] found a significant association of the Asp299Gly polymorphism with a risk of IBD and CD but not UC. In contrast, our analysis demonstrated a significantly higher 299G frequency in UC patients. However, the small number of studies available to date reduces our confidence in this conclusion to some extent. More studies on the association of this TLR4 variant and UC are needed in the Caucasian population to validate the conclusion.

Interestingly, as we mentioned above, the TLR4 Asp299 Gly polymorphism has recently been shown to be associated with decreased responsiveness to LPS in humans. In line with this observation, the TLR4 299Gly variation would be expected to inhibit the inflammatory response to Gram-negative bacteria and to protect against IBD development, which is on the contrary to the results of our meta-analysis. The underlying mechanism may involve the function of TLR4 in the regulation of immune 


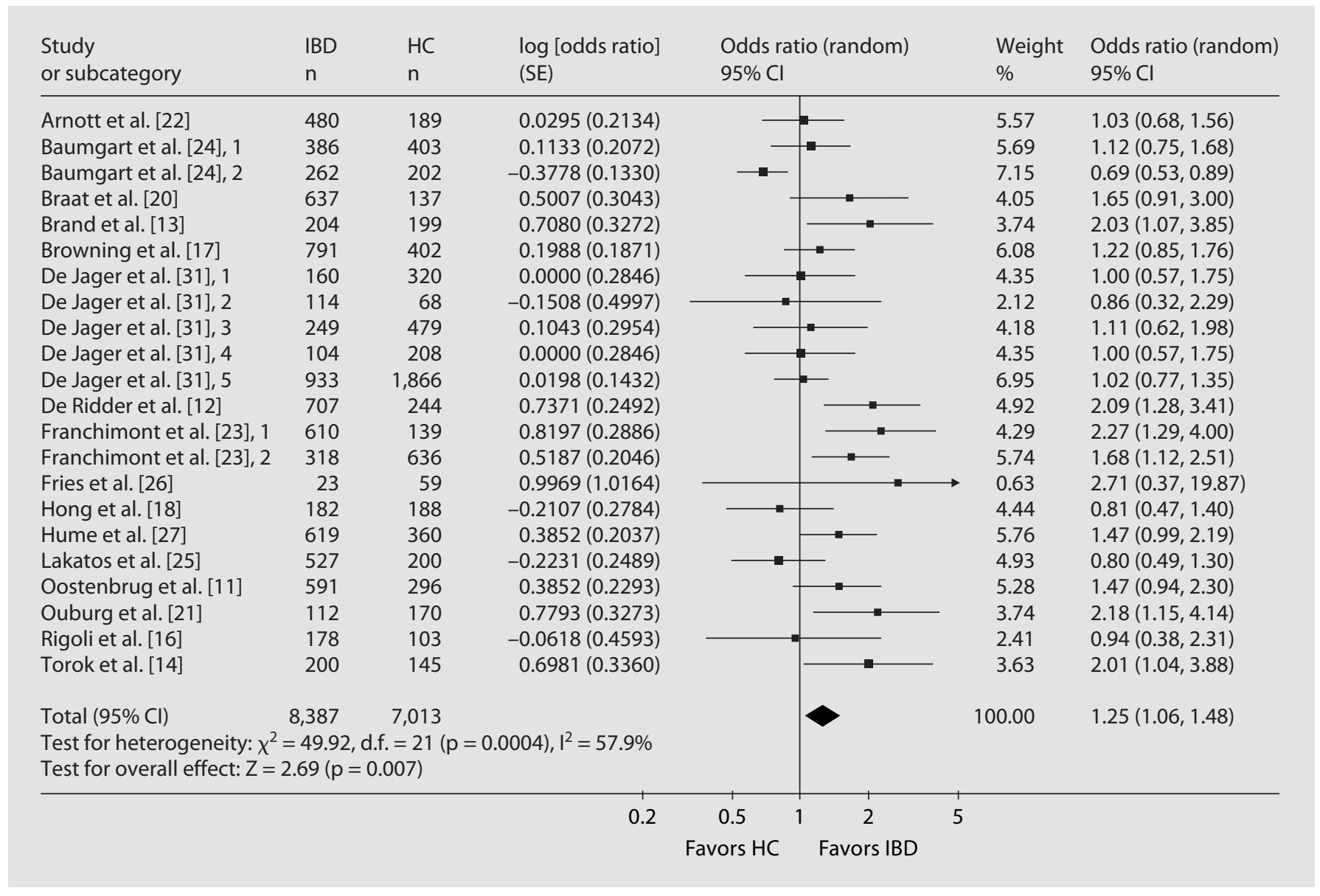

Fig. 3. Significant association between TLR4 299G allele and IBD risk (OR 1.25, 95\% CI 1.06-1.48, p = 0.007). Significant heterogeneity was shown among studies. $\mathrm{n}=$ Number of IBD patients or healthy controls (HC). The numbers after some of the study references are the cohort numbers.

responses to pathogens. The gut lumen is a major site of a large population of bacteria and the balanced state of coexistence is not autonomous but actively maintained by local protective mechanisms such as ongoing innate and adaptive immune responses [35]. Recently research carried out by Chieppa et al. [36], using dynamic explant and intravital two-photon imaging to study trans-epithelial DC extension into the small bowel, confirmed several previous reports [37-39] on the capacity of lamina propia DCs to send processes across the columnar epithelial layer without disruption of the tight junction between these cells and to interact with luminal microbial flora. They detected numerous DC processes in normal uninfected animals, which appeared to reflect an active response of DCs to local commensal flora and bacterial products. They also showed that microbial products required signaling via TLRs including TLR4 expressed by epithelial cells to evoke the DC response and that the signaling process was largely MyD88 dependent. In accord with these observations, Franchimont et al. [23] supposed that DC activation and maturation and the development of adaptive immunity require correct TLR 4 signaling and disruption of TLR4 signaling could engender an inappropriate innate and adaptive immune response necessary to ensure the state of coexistence which would result in a more severe inflammation. Research by Plotorak et al. [8] also provided convincing proof of this hypothesis: $\mathrm{CEH} /$ $\mathrm{HeJ}$ and $\mathrm{C} 57 \mathrm{BL} / 10 \mathrm{ScCR}$ mice bearing missense mutations of TLR4 are highly susceptible to dextran sodium sulfate-induced colitis.

The contribution of the T399I polymorphism to IBD is similar to D299G in the Caucasian population, which is in line with the finding that there is a strong linkage disequilibrium between Asp299Gly and Thr399Ile [40]. 
Nucleotide-binding oligomerization domain-2 (NOD2) has been identified as the candidate gene of CD. In addition to its role as receptor for the muramyl dipeptide component of peptidoglycan [41, 42], NOD2 also modulates signaling induced by TLRs $[43,44]$. Kullberg et al. [45] discovered that while peripheral blood mononuclear cells pre-incubated with NOD2 ligands were specifically downregulated for the production of tumor necrosis factor- $\alpha$ (TNF- $\alpha)$ induced by the TLR4 ligand LPS in CD patients with the wild-type NOD2 allele, the tolerance to LPS was absent in the cells of patients homozygous for the 3020insC NOD2 mutation, leading to uninhibited release of TNF- $\alpha$ by TLR4 ligands and intestinal bacteria. They proposed the absence of NOD2/TLR4 cross-tolerance as a potential mechanism for CD development. Hume et al. [27] also identified a novel NOD2 haplotype that strengthens the relationship between TLR4 A299G and CD. Therefore, to examine the impact of TLR4 SNPs on CD/UC susceptibility and phenotype, NOD2 polymorphisms should be detected at the same time to make the result more reliable. Certainly, this is also a shortcoming of our analysis. Provided with sufficient data of case-control studies concerning the TLR4 SNP association with CD stratified by NOD2, an additional stratified analysis by the presence of NOD2 mutations should be conducted to confirm the conclusion.

Genome-wide association (GWA) studies have recently yielded many positive associations with $\mathrm{CD}$ and UC. Duerr et al. [32] carried out the first GWA study of IBD and they observed highly significant association between $\mathrm{CD}$ and variants in the interleukin-23 receptor (IL-23R) on chromosome 1p31 in ileal CD cases of European ancestry. Specifically, a rare coding variant, rs11209026 (1142G>A; R381Q), was shown to confer a strong protective effect that was replicated in the same study in separate cohorts of patients with CD or UC [32]. Hampe et al. [33] reported an association analysis of 19,779 non-synonymous SNPs in a cohort of CD cases and controls in which they identified a significant association of a SNP in autophagy-related 16-like 1 (ATG16L1) on 2q37.1 (C/T, T300A). A later GWA study by Rioux et al. [34] replicated the associations of the two genes with IBD. In addition, they reported several new regions of strong association to $\mathrm{CD}$ encoding paired-like homeobox $2 \mathrm{~b}(\mathrm{PHOX} 2 \mathrm{~B})$, neutrophil cytosolic factor 4 (NCF4) and a predicted gene on 16q24.1 (FAM92B) [34]. The TLR4 gene was not found to be associated with IBD in the previous GWA studies; however, this is not surprising. Despite the potential of GWA studies to uncover modest genetic risk factors in complex disease, loci of a very modest genetic effect can be missed considering the limited sample sizes [46]. One example is the lack of significant GWA of the IBD5 haplotype in the GWA study by Rioux et al. [34], despite the fact that this is a confirmed CD risk haplotype.

Studies investigating the influence of TLR4 polymorphisms on disease characteristics of $\mathrm{CD}$ have reported some positive but discrepant results. Brand et al. [13] reported that the prevalence of a stricturing phenotype was increased in patients heterozygous for the TLR4 A299G polymorphism compared with patients with wild-type TLR4. Ouburg et al. [21] found carriage of TLR4 299G significantly increased the risk of colonic localization of CD. However, research by Hong et al. [18] detected no evidence that the variant TLR4 allele was associated with CD phenotypes. We did not identify any significant associations between CD phenotypes and 299Gly carriage, which is in line with the meta-analysis of Browning et al. [17]. Considering the small number of cases, we think any conclusion about the genotype-phenotype correlation is improper and unpersuadable now. The quality of phenotyping and the criteria used in disease classification can also influence the result to a large extent. There is overall agreement that $\mathrm{CD}$ is a chronically progressing disease and has a high tendency to change disease behavior with increasing disease duration. For instance, patients classified as having a nonstricturing, nonpenetrating disease phenotype have a high likelihood to progress over time to the more severe disease phenotypes (stricturing or penetrating) $[47,48]$. Without a long-term follow-up, the changing phenotype pattern will inevitably influence the judgment of phenotypes and limit the reliability of our conclusion. Recently, a new classification of CD, called the 'Montreal classification', has been suggested in an attempt to improve the existing Vienna classification [49]. This new classification has introduced changes in all three categories of the Vienna classification: age at diagnosis (A), disease location (L) and disease behavior (B). In detail, A1 (age $<40$ years) of the Vienna Classification was divided into two subgroups: age $<16$ years and $17-40$ years in the Montreal Classification. L4 (Upper gastrointestinal) was replaced by $\mathrm{L} 1+\mathrm{L} 4, \mathrm{~L} 2+\mathrm{L} 4$ and $\mathrm{L} 3+\mathrm{L} 4$. Perianal fistulas are no longer included in the penetrating disease category (B3) but are included as disease modifiers (indicated with the letter ' $p$ ') of the disease behavior variable [50]. The results of genotype-phenotype analysis may be different when using the Montreal Classification, especially for the analysis of disease behavior as there is a high incidence of perianal fistulas in CD patients which would be omitted from the subgroup of penetrating behavior. 
Some limitations should be discussed in this metaanalysis. First, heterogeneity may be present, influencing the results of meta-analysis, although a random effects model has been used. According to the test of heterogeneity, there was significant heterogeneity among studies in $\mathrm{CD}$ populations. Second, the numbers of subjects and studies included in the UC cohorts were small. There were only 10 and 6 studies derived from Caucasian populations for D299G and T399I polymorphisms, respectively, which may not have enough persuasion to show an association between the two SNPs and UC. Similarly, far more data are needed to identify the correlation between TLR4 variants and the clinical characteristics of IBD. Third, although the available genetic data implicate the TLR4 D299G and T399I polymorphisms as risk factors of CD susceptibility in Caucasian population, studies from other ethnic groups are needed to determine whether or not the two polymorphisms confer a risk for CD in other populations. We were not able to do meta-analyses in American and Asian ethnic groups due to the lack of studies or the failure to meet our inclusion criteria. Further studies on the association of the TLR4 D299G and T399I polymorphisms and IBD are needed in other ethnic populations.

In summary, our meta-analyses demonstrate that the TLR4 D299G and T399I polymorphisms may be significant risk factors for CD and UC in Caucasians. More studies are needed to determine the role of the two polymorphisms in UC, and stratification by NOD2 mutations are needed to confirm the conclusion. Considering the relatively small sample size, a larger trial is needed to identify the association between TLR4 299G and CD phenotypes. Further studies in various ethnic groups are also necessary to clarify the correlation between TLR4 D299G and T399I polymorphisms and CD and UC.

\section{References}

1 Medzhitov R, Preston-Hurlburt P, Janeway CA, et al: A human homologue of the Drosophila Toll protein signals activation of adaptive immunity. Nature 1997;388:394397.

-2 Aderem A, Ulevitch RJ: Toll-like receptors in the induction of the innate immune response. Nature 2000;406:782-787.

3 Cario E, Podolsky DK: Differential alteration in intestinal epithelial cell expression of toll-like receptor 3 (TLR3) and TLR4 in inflammatory bowel disease. Infect Immun 2000;68:7010-7017.

- 4 Hausmann M, Kiessling S, Mestermann S, et al: Toll-like receptors 2 and 4 are up-regulated during intestinal inflammation. Gastroenterology 2002;122:1987-2000.

-5 Frolova L, Drastich P, Rossmann P, et al: Expression of toll-like receptor 2 (TLR2), TLR4, and CD14 in biopsy samples of patients with inflammatory bowel diseases: upregulated expression of TLR2 in terminal ileum of patients with ulcerative colitis. J Histochem Cytochem 2008;56:267-274.

-6 Hart AL, Al-Hassi HO, Rigby RJ, et al: Characteristics of intestinal dendritic cells in inflammatory bowel disease. Gastroenterology 2005;129:50-65.

7 Chow JC, Young DW, Golenbock DT, et al: Toll-like receptor-4 mediates lipopolysaccharide-induced signal transduction. J Biol Chem 1999;274:10689-10692.

-8 Poltorak A, He X, Smirnova I, et al: Defective LPS signaling in $\mathrm{C} 3 \mathrm{H} / \mathrm{HeJ}$ and $\mathrm{C} 57 \mathrm{BL} /$ $10 \mathrm{ScCr}$ mice: mutations in TLR4 gene. Science 1998;282:2085-2088.
$\$ 9$ Arbour NC, Lorenz E, Schutte BC, et al: TLR4 mutations are associated with endotoxin hyporesponsiveness in humans. Nat Genet 2000;25:187-191.

10 Lappalainen M, Halme L, Turunen U, et al: Association of IL23R, TNFRSF1A, and HLADRB1*0103 allele variants with inflammatory bowel disease phenotypes in the Finnish population. Inflamm Bowel Dis 2008; 14 : 1118-1124.

11 Oostenbrug LE, Drenth JPH, De Jong DJ, et al: Association between Toll-like receptor 4 and inflammatory bowel disease. Inflamm Bowel Dis 2005; 11:567-575.

12 De Ridder L, Weersma RK, Dijkstra G, et al: Genetic susceptibility has a more important role in pediatric-onset Crohn's disease than in adult-onset Crohn's disease. Inflamm Bowel Dis 2007;13:1083-1092.

13 Brand S, Staudinger T, Schnitzler F, et al: The role of Toll-like receptor 4 Asp299Gly and Thr399Ile polymorphisms and CARD15/ NOD2 mutations in the susceptibility and phenotype of Crohn's disease. Inflamm Bowel Dis 2005;11:645-652.

14 Torok HP, Glas J, Tonenchi L, et al: Polymorphisms of the lipopolysaccharide-signaling complex in inflammatory bowel disease: association of a mutation in the Toll-like receptor 4 gene with ulcerative colitis. Clin Immunol 2004;112:85-91.

15 Gazouli M, Mantzaris G, Kotsinas A, et al: Association between polymorphisms in the Toll-like receptor 4, CD14, and CARD15/ NOD2 and inflammatory bowel disease in the Greek population. World J Gastroenterol 2005;11:681-685.
16 Rigoli L, Romano C, Caruso RA, et al: Clinical significance of NOD2/CARD15 and Toll-like receptor 4 gene single nucleotide polymorphisms in inflammatory bowel disease. World J Gastroenterol 2008; 14:44544461.

17 Browning BL, Huebner C, Petermann I, et al: Has toll-like receptor 4 been prematurely dismissed as an inflammatory bowel disease gene? Association study combined with meta-analysis shows strong evidence for association. Am J Gastroenterol 2007;102: 2504-2512.

18 Hong J, Leung E, Fraser AG, et al: TLR2, TLR4 and TLR9 polymorphisms and Crohn's disease in a New Zealand Caucasian cohort. J Gastroenterol Hepatol 2007;22:1760-1766.

19 Xue HP, Ni PH, Wu JM, et al: Gene polymorphisms of Toll like receptors in inflammatory bowel disease and their distribution in different populations. J Shanghai Jiaotong Univ (Med Sci) 2007;27:1226-1231.

20 Braat H, Stokkers P, Hommes T, et al: Consequence of functional Nod2 and TLR4 mutations on gene transcription in Crohn's disease patients. J Mol Med 2005;83:601-609.

21 Ouburg S, Mallant-Hent R, Crusius JBA, et al: The toll-like receptor 4 (TLR4) Asp299Gly polymorphism is associated with colonic localisation of Crohn's disease without a major role for the Saccharomyces cerevisiae mannan-LBP-CD14-TLR4 pathway. Gut 2005;54: 439-440. 
-22 Arnott IDR, Nimmo ER, Drummond HE, et al: NOD2/CARD15, TLR4 and CD14 mutations in Scottish and Irish Crohn's disease patients: evidence for genetic heterogeneity within Europe? Genes Immun 2004;5:417425.

-23 Franchimont D, Vermeire S, Housni HE, et al: Deficient host-bacteria interactions in inflammatory bowel disease? The toll-like receptor (TLR)-4 Asp299gly polymorphism is associated with Crohn's disease and ulcerative colitis. Gut 2004:53:987-992.

24 Baumgart DC, Büning C, Geerdts L, et al: The c.1-260C $1 \mathrm{~T}$ promoter variant of CD14 but not the c.896A 1 G (p.D299G) variant of Toll-LIKE Receptor 4 (TLR4) genes is associated with inflammatory bowel disease. Digestion 2007;76:196-202.

25 Lakatos PL, Lakatos L, Szalay F, et al: Tolllike receptor 4 and NOD2/CARD15 mutations in Hungarian patients with Crohn's disease: phenotype-genotype correlations. World J Gastroenterol 2005;11:1489-1495.

-26 Fries W, Renda MC, Maria A, et al: Intestinal permeability and genetic determinants in patients, first-degree relatives, and controls in a high-incidence area of Crohn's disease in southern Italy. Am J Gastroenterol 2005;100: 2730-2736.

27 Hume GE, Fowler EV, Doecke J, et al: Novel NOD2 haplotype strengthens the association between TLR4 Asp299Gly and Crohn's disease in an Australian population. Inflamm Bowel Dis 2008;14:585-590.

$\checkmark 28$ Figueroa C, Peralta A, Herrera L, et al: NOD2/CARD15 and Toll-like 4 receptor gene polymorphism in Chilean patients with inflammatory bowel disease. Eur Cytokine Netw 2006;17:125-130.

-29 Xiong LF, Xia B, Jiang L, et al: No association of TLR4 gene Asp299Gly, TLR2 gene Arg753Glu and Arg677Trp polymorphisms with inflammatory bowel disease in Chinese Han population Hubei Province. World J Chin Dig 2006;14:212-215.
30 Riis L, Vind I, Vermeire S, et al: The Prevalence of genetic and serologic markers in an unselected European population-based cohort of IBD patients. Inflamm Bowel Dis 2007;13:24-32.

-31 De Jager PL, Franchimont D, Waliszewska A, et al: The role of the Toll receptor pathway in susceptibility to inflammatory bowel diseases. Genes Immun 2007;8:387-397.

32 Duerr RH, Taylor KD, Brant SR, et al: A genome-wide association study identifies IL23R as an inflammatory bowel disease gene. Science 2006;314:1461-1463.

33 Hampe J, Franke A, Rosenstiel P, et al: A genome-wide association scan of nonsynoymous SNPs identifies a susceptibility variant for Crohn disease in ATG16L1. Nat Genet 2007;39:207-211.

34 Rioux JD, Xavier RJ, Taylor KD, et al: Genome-wide association study identifies new susceptibility loci for Crohn disease and implicates autophagy in disease pathogenesis. Nat Genet 2007;39:596-604.

35 Lamm ME: Interaction of antigens and antibodies at mucosal surface. Annu Rev Microbiol 1997;51:311-340.

36 Chieppa M, Rescigno M, Huang AYC, et al: Dynamic imaging of dendritic cell extension into the small bowel lumen in response to epithelial cell TLR engagement. J Exp Med 2006;203:2841-2852.

37 Vallon-Eberhard A, Landsman L, Yogev N, et al: Transepithelial pathogen uptake into the small intestinal lamina propria. J Immunol 2006;176:2465-2469.

38 Rescigno M, Urbano M, Valzasina B, et al: Dendritic cells express tight junction proteins and penetrate gut epithelial monolayers to sample bacteria. Nat Immunol 2001;2: 361-367.

39 Rescigno M, Rotta G, Valzasina B, et al: Dendritic cells shuttle microbes across gut epithelial monolayers. Immunobiology 2001; 204:572-581.

40 Levinson DF, Kirby A, Slepner S, et al: Simulation studies of detection of a complex disease in a partially isolated population. Am J Med Genet 2001;105:65-70.
41 Girardin SE, Boneca IG, Viala J, et al: Nod2 is a general sensor of peptidoglycan through muramyl dipeptide (MDP) detection. J Biol Chem 2003;278:8869-8872

42 Inohara N, Ogura Y, Fontalba A, et al: Host recognition of bacterial muramyl dipeptide mediated through Nod2. Implications for Crohn's disease. J Biol Chem 2003;278:55095512.

43 van Heel DA, Ghosh S, Hunt K, et al: Muramyl dipeptide and toll-like receptor sensitivity in NOD2-associated Crohn's disease. Lancet 2005;365:1794-1796.

44 Netea MG, Ferwerda G, De Jong DJ, et al: NOD2 modulates specific Toll-like receptor pathways for the induction of cytokine release. J Immunol 2005;174:6518-6523.

45 Kullberg BJ, Ferwerda G, de Jong DJ, et al: Crohn's disease patients homozygous for the 3020insC NOD2 mutation have a defective NOD2/TLR4 cross-tolerance to intestinal stimuli. Immunology 2007;123:600-605.

$\checkmark 46$ Wang WY, Barratt BJ, Clayton DG, et al: Genome-wide association studies: theoretical and practical concerns. Nat Rev Genet 2005; 6:109-118.

47 Louis E, Collard A, Oger AF, et al: Behaviour of Crohn's disease according to the Vienna classification: changing pattern over the course of the disease. Gut 2001;49:777-782.

$\checkmark 48$ Cosnes J, Cattan S, Blain A, et al: Long-term evolution of disease behaviour of Crohn's disease. Inflamm Bowel Dis 2002;8:244250 .

49 Silverberg MS, Satsangi J, Ahmad T, et al: Toward an integrated clinical, molecular and serological classification of inflammatory bowel disease: report of a Working Party of the 2005 Montreal World Congress of Gastroenterology. Can J Gastroenterol 2005; 19(suppl A):5-36.

50 Katsanos KH, Tsianos EV: From Vienna to Montreal: the new Crohn's disease classification. Ann Gastroenterol 2006;19:143-144. 